\title{
Improvement of Academic Performance of Engineering Students through an Adaptive Educational Hypermedia System (AEHS)
}

\author{
Brayan Calcina, Ciro Rodriguez,Doris Esenarro
}

\begin{abstract}
This paper describes how to improve the academic performance of engineering university students through an Adaptive Educational Hypermedia System (AEHS). The psychological basis, learning styles and MOOMH methodology for the development of the system are exposed, which with its implementation achieves adaptability and works for students as an "intelligent tutor", allowing them to guide their education as academic tutor. Not only shows its content that meets the needs of the student, but it is also represented in elements such as color adaptation, work tools and even academic recommendations based on the interactions that the user makes within the system, the system recognizes its pattern of use, and when the student is logged in again, it presents a friendlier interface that the student prefers use, it is wider in content and, above all, easy to use and understand. In addition, the AEHS allows to extend education allowing the assignment of more domain areas, in the field of engineering, that is, the SHAE can be adapted to various engineering specialties such as: industrial, software, telecommunications, mechanics and other.
\end{abstract}

Keywords: Adaptive Educational Hypermedia, learning styles, MOOMH, educational software, adaptive software.

\section{INTRODUCTION}

In Peru, university education is not a privilege that most people can access. The problem arises either because the state does not directly support university education or because of the same student's neglect.

Faced with this problem, educational technological tools try to help solve these types of problems by increasing the academic level of students through mobile applications or web systems capable of educating young people at a level similar or higher than that of a teacher. Based on all this, the Adaptive Software is born, which more specifically will be defined as an Adaptive Hypermedia Educational System (AEHS), which will adapt the content, user interfaces, search tools and guided teaching in particular for each type of user (student). This will be achieved by establishing pedagogical rules to know the learning style of each student, their academic level and how they perceive the information better (texts, videos, sounds, etc.).
Revised Manuscript Received on 14 September, 2019.

Brayan Calcina,NationalUniversity Mayor de San Marcos, Lima, Peru.(E-mail: brayan.calcina@unmsm.edu.pe)

Ciro Rodriguez,NationalUniversity Mayor de San Marcos, Lima, Peru.(E-mail: crodriguezro@unmsm.edu.pe)

Doris Esenarro,NationalUniversity Federico Villarrea, Lima.,Peru(Email: desenarro@unfv.edu.pe)

\section{METHODOLOGY}

\subsection{Learning styles}

Since ancient times it has been established that all people learn differently, that is, they have different learning styles. This leads to a question: How can we capture the learning style of all people? That is, to be able to capture these learning styles and introduce them as a psychological basis for a computer system and that it can emit content that is suitable for each user. There are people who learn more by watching video tutorials on the internet, others through reading (theoretical learning), also people who learn through examples and experiences (practical learning). This leads us to conclude that if a system presents information that suits each user, it will lead to a more meaningful and solid learning for each student. So, considering the different learning styles that each person possesses, we focus on the Felder and Silverman model to establish the different types of [12] "learning styles". This model tells us that there are 5 dimensions of learning styles, as shown in Table 1 
Table 1. Model of types of learning according learning styles according to Felder and Silverman

\begin{tabular}{|c|c|}
\hline Dimension 1 & Description \\
\hline - Sensitive & $\begin{array}{l}\text { Accurate, functional, realistic, oriented towards facts and procedures; they prefer to } \\
\text { solve the problems through correctly formulated procedures; they have perfectionist } \\
\text { characteristics emphasizing detail; they prefer practical activities (simulation work, for } \\
\text { example); they have the power to memorize things. They are very realistic, so they } \\
\text { prefer courses whose knowledge applies to the real world. }\end{array}$ \\
\hline - Intuitive & $\begin{array}{l}\text { Creative, theoretical, emphasize theory, elements with their own meaning. They love } \\
\text { new things and hate doing the same thing over and over again. They like to raise or } \\
\text { discover new ways to solve a problem; conceptualize better through the abstraction of } \\
\text { reality through mathematics or other sciences. They don't like the idea of memorizing } \\
\text { things and taking calculus courses. }\end{array}$ \\
\hline \multicolumn{2}{|r|}{8} \\
\hline - $\quad$ Visual & $\begin{array}{l}\text { To obtain information and knowledge opt for visual models, charts, concept maps, } \\
\text { diagrams, flowcharts, etc. Theyhavephotographicmemory. }\end{array}$ \\
\hline - Verbal & $\begin{array}{l}\text { They like to learn through conversations, face-to-face classes, also through reading. } \\
\text { Theyunderstandwrittenorspokeninformationbetter. }\end{array}$ \\
\hline \multicolumn{2}{|r|}{ 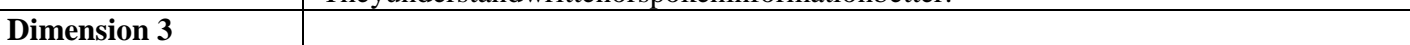 } \\
\hline - $\quad$ Active & $\begin{array}{l}\text { They learn best when they make use of information or knowledge in order to explain, } \\
\text { expose, discuss them with other people. }\end{array}$ \\
\hline - Reflexives & $\begin{array}{l}\text { They increase their knowledge when they retain and understand information that has } \\
\text { been processed by themselves through reflection on it. } \\
\text { Theypreferlonelinesstolearnbetter. }\end{array}$ \\
\hline \multicolumn{2}{|l|}{ Dimension 4} \\
\hline - Sequential & $\begin{array}{l}\text { Follow a line to learn, that is, learn step by step and the next knowledge you acquire } \\
\text { must be related to the previous one. To solve a problem follow small logical sequences } \\
\text { to reach it. }\end{array}$ \\
\hline - Global & $\begin{array}{l}\text { They learn things a lot and without having it planned. They can solve very complex } \\
\text { problems very quickly and place things creatively, although they have problems } \\
\text { explaining how they did it. }\end{array}$ \\
\hline \multicolumn{2}{|r|}{ 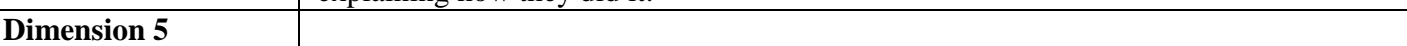 } \\
\hline - Inductive & $\begin{array}{l}\text { They understand the information that goes from the particular to the general, that is, } \\
\text { they learn best when the information is at its lowest level (facts) and then they can } \\
\text { understand the principles or methodologies that carry this information. }\end{array}$ \\
\hline - Deductive & $\begin{array}{l}\text { They learn the information that goes from the general to the particular, that is, they go } \\
\text { from generalizations to facts. }\end{array}$ \\
\hline
\end{tabular}

Based on this model we can establish the types of learning style that exist through an entry questionnaire formulated in the system. This questionnaire will allow the identification of the student's learning style and may adapt the content for each user according to their learning style.

\subsection{Types of content}

We live in an era governed by the internet and where information is no longer found only in books and libraries, today the information is located in virtual repositories (private servers and the cloud) to which they have a very high percentage of people in all the world. Perhaps the best known and used repository in Peru, to store information in the cloud, is Google Drive that allows us to upload files and work with online office documents.

So, thanks to technological advances, we can talk about types of files that can be read on a computing device. These files are known as multimedia elements.

Now, there are different multimedia elements, such as videos, office documents (Word, Excel, Power Point), PDF, images (2D and 3D), audios, etc. But why is it important to identify the types of multimedia files? Adaptive Hypermedia Systems need to present adaptive information to people, for this they need to know two very important things: Their learning style and their academic performance. The learning style will allow the system to adapt the content according to the user's preferences, either by showing Office files or video tutorials. On the other hand, we have the academic performance that will allow the system to identify the academic level that its content must have. An example of this would be the following: If an engineering student has a visual learning style, then the material that will be presented to him for his learning must be structured in tables or diagrams that are to his liking and of his easy understanding, but not just show something pleasant to the eye and easy to understand for him, we must bear in mind that all students, despite being university students and taking the same course in the same cycle, do not have the same academic performance so the material that must be presented must meet your needs and that is where academic performance becomes a fundamental piece of learning.

That is why our implementation of a SHAE takes as a fundamental basis learning styles and academic performance since these are the important pieces for the construction of said system.

In conclusion, we can say that if a person learns better by watching video tutorials, the SHAE must present this type of information as the main recommendation to get ahead to solve the academic needs of the students. 


\subsection{Adaptive Hypermedia Educational System}

The best definition of an adaptive hypermedia educational system is given by the following statement.

"An educational hypermedia adaptive system is a system that studies the techniques that can be applied in hypermedia systems, so that they adapt to the user who connects, also systems of this type keep a model of each user with their characteristics (level of knowledge , etc.), which represents an advantage to facilitate learning, since it is currently necessary to propose strategies that involve the incorporation of Web technology in the education process, allowing it to be more effective and even more when said technology is focused on allowing the user to navigate finding information that allows them to acquire knowledge in their area of interest ". (Buitrago, 2010).

Buitrago mentions that these systems are made up of three (3) components: the Domain Model, the User Model, and the Adaptation Model.

- Domain Model: This model organizes the knowledge that will be transmitted and is responsible for storing information by concepts, attributes and existing relationships with other concepts. Domain or content models may have a conglomerate of unrelated concepts, or they may have concepts closely related to others, forming a kind of semantic network. "Educational systems often use prerequisites that are linked to the concept; to advance to another concept you need to have known one or several previous notions". (Buitrago, 2010).

- User Model: It allows representing the existing relationship of each user with the knowledge that will be transmitted. To achieve this, it stores and structures significant characteristics of each user. "These aspects, called attributes, are stored in table-type entities that relate each user to their characteristics and to the concepts of the Domain Model". (Buitrago, 2010).

- Adaptation Model: "Both types of adaptation, content and navigation, execute rules that specify what and how system elements should be displayed and behaved considering the user model." (Buitrago, 2010).

\section{ACADEMIC LEVEL ESTABLISHMENT}

\subsection{Level of learning of university students in Peru}

Secondary education is the beginning of university life for a student. Unfortunately, in our country the majority of young people do not finish high school optimally to be able to take an admission exam and efficiently carry out a university degree. According to the indicators evaluated by the Organization for Economic Cooperation and Development (OECD), $60 \%$ of students have reading comprehension problems, $68.5 \%$ in science and $74.6 \%$ in mathematics.

According to the result of the PISA 2012 test, we are ranked 65 in the General Ranking of nations worldwide and the last place in Latin America.

Our AESH is oriented to help young people by presenting material adapted to their learning style and academic level. The logical structure of the system is presented below.

\subsection{Logical system structure}

Next, we will explain what this logical structure consists of in order to identify the student's academic level.

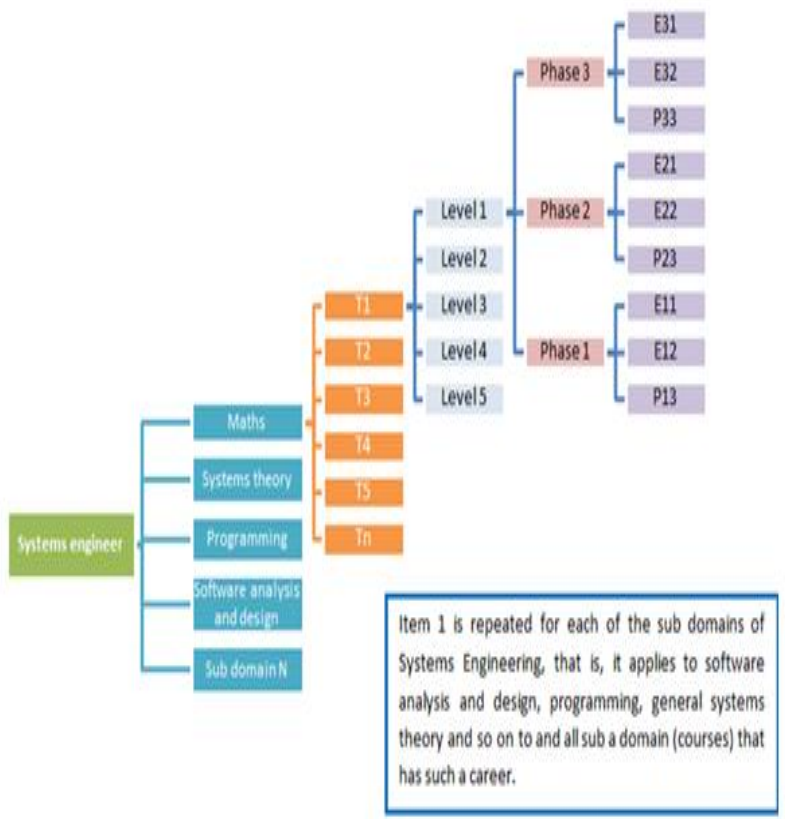

Figure 1. Logical structure of the Educational Adaptive Hypermedia System

A domain is established, as an example, the field of systems engineering will be taken. This domain is then divided into its 4 sub domains: Mathematics, Programming, Systems Theory and Software Analysis and Design. Each sub domain will have a set of related topics (T1, T2, T3, ...,Tn), for example, the sub domain of mathematics can be Derived, Limits, Vectors, etc. 5 levels of learning are established for each topic.

The 5 levels of learning are classified as follows:

- Level 1: Basic / Beginner Level

- Level 2: Basic average level

- Level 3: Upper middle level

- $\quad$ Level 4: Basic upper level

- $\quad$ Level 5: Top expert level

Each level of learning will have 3 phases associated. These phases are the ones that will help to take the student's learning along the right path since at the end of the 3 phases; the student will have fully understood the subject. Each of these phases contains the following value:

- $\quad$ Phase 1: Theoretical

- $\quad$ Phase 2: Practical

- $\quad$ Phase 3: Application

In Phase 1 (theoretical), theoretical content material will be presented, that is, concepts and principles of the chosen theme. In Phase 2 (Practical) examples and exercises of the chosen topic will be presented, this will help to put into practice the knowledge acquired in Phase 1. Finally, in Phase 3 (application), exercises and readings will be presented that will reflect the application of the topic chosen in reality and how these are useful for society. 
E11, E12... E1n; E21, E22... E2n; E31, E32 ... E3n will be the multimedia content presented in each of the phases. You must understand that as it is an Adaptive System, the contents presented must respect the student's learning styles by showing relevant material for their correct understanding.

P11, P22 and P33 are the 3 assessments that will be carried out at the end of each of the phases, this will let you know if the student successfully completed each phase and is prepared for the next level of learning. At the end of the 3 phases a final exam will be presented that will combine concepts of the theoretical, practical and application phase. It is worth mentioning that each of the phases is iterative, that is, if the student fails to pass a phase successfully, they can return to the previous one and review the contents presented in it.

As this process is iterative, it allows the student to learn the subject much better since the system must be in constant interaction with the student by showing him material that, not only will he like, but will also be in accordance with the academic level he presents. It is as if a tutor was guiding your learning using an assertive language, material according to your academic level and that by it' self will begin to learn from you so that you can understand the subject in the most optimal way possible.

Therefore, these 3 phases will help not only the student to understand the subject, but also to understand how the learning obtained can be applied in day-to-day activities and how they help our reality to grow in all existing social pillars (financial, technological, educational, social, etc.)

\section{METHODOLOGY FOR THE DEVELOPMENT OF THE ADAPTIVE EDUCATIONAL HYPERMEDIA SYSTEM\& RESULTS}

\subsection{Introduction to the MOOMH methodology}

It was proposed by Benigni in 2012. It allows developing hypermedia educational applications and representing the elements very clearly. The MOOMH methodology consists of (4) phase models: Requirement Model, Analysis Model, Design Model and Implementation Model, as the basis for the development of educational and informative applications in this case for the Web. It is imperative to note that the models of the classic user modeling cycle in adaptive systems will be incorporated into the respective phases of MOOMH where they are inherent.

The models that integrate MOOMH are interrelated, allowing it to be iterative between each of its phases, therefore there is interaction between them, (see Figure 2). The MOOMH Methodology models are: 1) Requirements, 2) Analysis, 3) Design, 4) Implementation. (a)

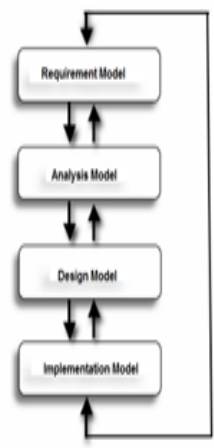

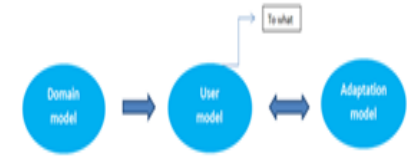

(b)

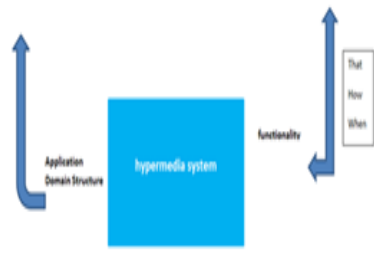

Figure 2.Interrelation of MOOMH models (a) and Components of Adaptive Hypermedia Systems (SHA)respectively (b). Taken from "MOOMH: Methodology Oriented to Multimedia and Hypermedia Objects" Benigni, 2012.

\subsection{Models established in MOOMH}

1. Requirements model: The requirements model represents the fundamental basis on which our Adaptive Hypermedia System focuses, determines who our software or application is aimed at. It is composed of 2 phases: Study of the feasibility and determination of the requirements of the problem. On the other hand, we will add the Domino Model as part of the elements or components in the development of Adaptive Hypermedia Systems (SHA), in this way we will be able to model and / or structure in much more general principles (concepts) our CUS (cases of use) and its components (attributes and relationships), obtaining a manageable grouping of the concepts in categories such as, atomic, compound and relationship to represent in a more concise, efficient and understandable way the clusters (blocks) of administration obtained.

a) Feasibility study: Here we determine what the needs of our system are and evaluate their feasibility, which is established based on the necessary elements or resources available to carry out the elaboration of the prototypes of the system. This point allows us to assess whether the system is feasible or viable.

b) Determination of requirements: All data and information collected through our use cases are analyzed here. Keep in mind that the use case diagrams are made up of the following elements:

b.1) Use cases: These reflect how users will use the system. Determine what the functions of our software or application will be in all cases evaluated according to the needs of Stakeholders.

b.2) Actors: They are responsible for executing the functionalities described in the use cases. They can be personal, computer systems (software or hardware).

b.3) Relations: They are the relationships that exist between use cases. These relationships can be of different types: <<include>>, <<extends>>, <<use>>, $<<$ communicate $>>$. 
2. Analysis model: In this model, the different tasks of all users (students) will be modeled or structured and is composed of three phases: I. Recognition of objects, II. System navigation map design and III. Elaboration of the objects.

I. Recognition of the objects: In this stage the definition of the objects and the establishment of the relationship between them will be carried out, which are recognized thanks to the association between the existing objects. "These associations represent links, hyperlinks or ramifications to other administrative blocks; these objects are nothing more than the possible global windows or metaphors that the application will have at the beginning of the design" (Benigni, 2012). Through the interrelation that will exist between the different models, these objects and their associations will regroup based on the needs established by the end users (students).

II. Design of the navigation map of the system: In order for the system to adapt to the users, a navigation graph was constructed, which obeys a set of rules, will be responsible for displaying the corresponding (adapted) information to the students. Each node of our graph represents a course or subject that will be studied.

III. Preparation of the objects: After correctly establishing the analysis model, we proceed to the elaboration (design) of the objects identified based on the multimedia elements (video, text, animation, image, sound, etc.). "This phase allows representing in a simple way the lessons, information units or administrative blocks, specifying a design language for it" (Benigni, 2012). To proceed with the design part, a multimedia design language will be used that will allow the design of the prototypes (initially recommended on paper) and then go on to a highlevel representation with the use of FrameWorks exclusive for it.

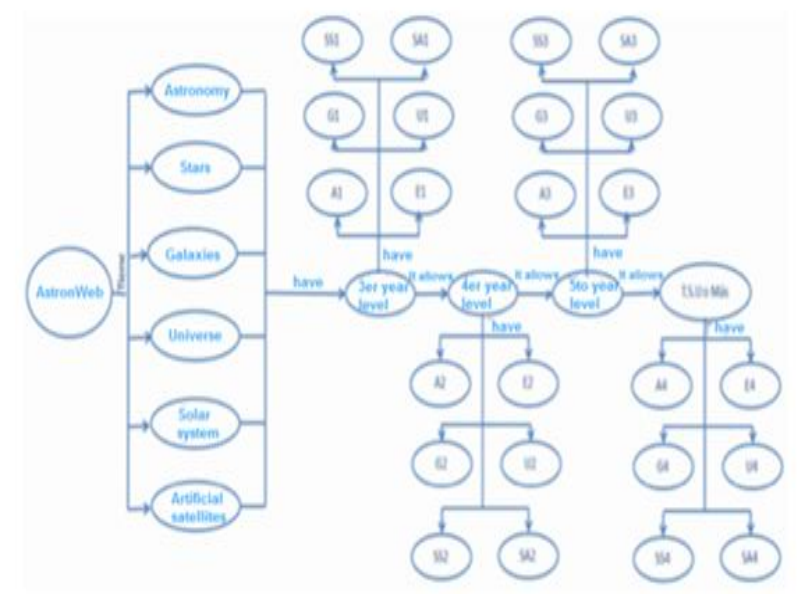

Figure 4.Navigation graph for Adaptive Software. Taken from "MOOMH: Methodology Oriented to Multimedia and Hypermedia Objects" Benigni, 2012.

3. Design Model: After the design of the first sketches of the previous prototypes made at a low level, they are improved and the logical integration of the computer equipment is carried out. This model is composed of three (3) phases, which can be mutually exclusive; Depending on the application, these are: a) Interface prototype, b)
Database design and c) Web modeling. For a better design, the User Model and the Adaptation Model will be added, because the "User Model allows storing user highlights such as preferences, interests and even the routes and interaction that the user makes with the system, allowing the user to Adaptation model based on what has already been stored, adapt the information or content to be displayed according to each user." (Benigni, 2012)

4. Implementation Model: In this model all the necessary computational components are identified and the source code of our system must be elaborated, to achieve this, a thorough evaluation must be carried out. For a better design it is recommended to elaborate the programmer manual or software manual. In this model the phases of writing or elaboration of the source code, architecture design or OSI layers are defined, we must determine which OSI layer will be implemented by the software under development, obtaining greater versatility and independence in the operations process of the application.

\subsection{Mathematical model for the calculation of user profiles}

The mathematical model that is intended to be used for the development of this system is based on the Pearson correlation coefficient. From the database a list of neighbors is constructed, of which the preferences are combined to generate a list with the $\mathrm{N}$ elements most recommended for the current user. This technique has the disadvantage of requiring a minimum number of users with a minimum number of predictions each, including the user for whom the recommendation is intended.

Because of its fundamental importance, it is necessary that the function Get_Similarity_Between_user () measure the similarities of all users with the current user. To achieve this objective, the Pearson Correlation Coefficient is used This is derived from the linear regression formulas and assumes that the relationship between elements is linear, the independent errors and the distribution have constant and average variance 0 . It is evident that these assumptions usually do not really occur with what needs to be assessed: how affect the goodness of the results; but, in a large number of cases, the performance that Pearson uses is appropriate. (A. Cortez, 2016)

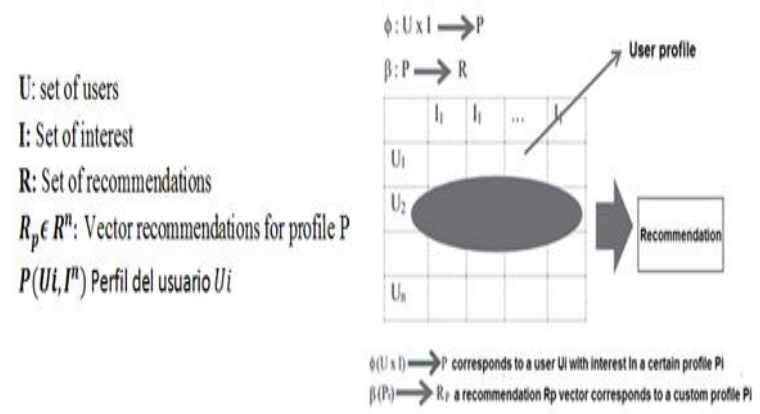

Figure 5. User profile mapping and recommendations. Cortez, 2016 


\section{REFERENCES}

1. Martínez, E. y Mortero, A. (2015) Adaptive Hypermedia System for learning advanced information searches on the internet. Educaré, 20 (1). 81 - 107. Available: http://revistas.upel.edu.ve/index.php/educare/article/view File/4726/247 3, (2015)

2. Santis, A. y Gonzales, S. Design and implementation of a mobile application based on adaptive hypermedia (sha) systems supported by the shakmaleon platform for the android operating system. University of Córdoba, Spain. Available:

http://repositorio.unicordoba.edu.co/handle/123456789/6 53, (2014)

3. Cortez, A. (2016). Learning systems based on adaptive hypermedia environments. Ricardo Palma University, Peru. Available: http://revistas.urp.edu.pe/index.php/Perfiles_Ingenieria/ar ticle/view/819, (2016)

4. Benigno, G. y Marcano, I. (2014). What tools to use to design adaptive hypermedia educational systems? Gladys Benigno y IngrithMarcano. Espacios, 35 (6), Educador. Available:

http://www.revistaespacios.com/a14v35n06/14350613.ht $\mathrm{ml}$

5. Lerís, D., Vea, F., y Ángeles, G. (2015). Adaptive learning in moodle: three practical cases. Education in the knowledge society (EKS). 16 (4), España. Available: http://revistas.usal.es/index.php/revistatesi/article/view/e ks2015161381 57, (2014)

6. Dwi, H. (2014). The design and implementation of an adaptive e-learning system. UniversitasNegeri Yogyakarta, Indonesia. (2014) https://www.researchgate.net/publication/228956078

7. Battou, A. (2017). Design of an adaptive learning system based on a balanced combination of agile learning design and student-centered approach. American Scientific Research Journal for Engineering, Technology, and Sciences (ASRJETS). 37 (1). 178 - 186. Available: http://asrjetsjournal.org/index.php/American_Scientific_J ournal/article /view/3519, (2017)

8. Santis, A., y Gonzales, S. (2014). DESIGN AND Implementation of a mobile application based on adaptive hypermedia systems (SHA) supported by the shakmaleon platform for the android operating system. University of Córdoba, Colombia. Available: http://repositorio.unicordoba.edu.co/

9. Ministry of Education. (2016). Secondary Education curriculum. Available: http://www.minedu.gob.pe/curriculo/pdf/programacurric ular-educacion-secundaria.pdf

10. [Guadalupe, C., León, J., Rodríguez, J., y Vargas, S. (2017). Analysis and perspectives of basic education. Strengthening education management in Peru. Available: http://www.grade.org.pe/forge

11. Graf, S., Viola, R., Kinshuk, y Leo, T. (2006). Representative characteristics of feldersilverman learning styles: an empirical model. Available: https://s3.amazonaws.com/academia.edu.documents/354 $\underline{54692 /}$

\section{AUTHORS}

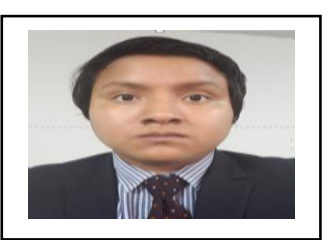

Brayan Esthiver Calcina Aguilar

Member of the artificial intelligence research group of the faculty of systems engineering at the National University Mayor de San Marcos, working as System Analyst / Programmer with experience in intelligent systems development

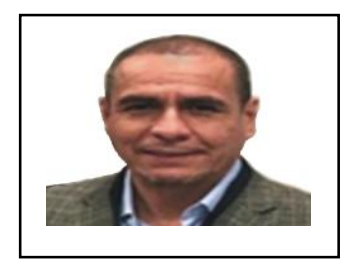

Ciro Rodriguez Rodriguez

Professor at the School of Software Engineering at the National University Mayor de San Marcos and also at the Computer Science School and Graduate School of the National University Federico Villarreal, with science studies at the Abdus Salam International Center for Theoretical Physics (ICTP) and the United States Particle Accelerator School (USPAS)

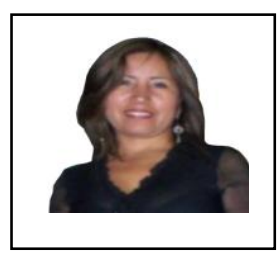

Doris Esenarro Vargas

Professor at the Faculty of Environmental Engineering and Graduate School of the National University Federico Villarreal, with studies in System Engineering, Architecture and Environmental Engineering 